\title{
Effects of Soil-Foundation-Structure Interaction on Seismic Structural Response via Robust Monte Carlo Simulation
}

\author{
M. Moghaddasi K..$^{*}$, M. Cubrinovski ${ }^{1}$, J.G. Chase $^{2}$, S. Pampanin ${ }^{1}$, \\ A. Carr $^{1}$ \\ ${ }^{1}$ Department of Civil and Natural Resources Engineering, University of Canterbury, Private Bag \\ 4800, Christchurch 8140, New Zealand, Tel. (+64) 3-364-2250 \\ ${ }^{2}$ Mechanical Engineering Department, University of Canterbury, Private Bag 4800, \\ Christchurch 8140, New Zealand, Tel. (+64) 3-364-2596
}

For the definitive version, see:

Moghaddasi, M., Cubrinovski, M., Chase, J.G., Pampanin, S. and Carr, A. (2011) Effects of soil-foundation-structure interaction on seismic structural response via robust Monte Carlo simulation. Engineering Structures, 33(4), 1338-1347. http://dx.doi.org/10.1016/j.engstruct.2011.01.011.

\begin{abstract}
\footnotetext{
${ }^{1}$ Corresponding author. Tel. (+64) 3-364-2250.

E-mail address: masoud.moghaddasi@pg.canterbury.ac.nz
}

Uncertainties involved in the characterization and seismic response of soil-foundationstructure systems along with the inherent randomness of the earthquake ground motion result in very complex (and often controversial) effects of soil-foundation-structure interaction (SFSI) on the seismic response of structures. Conventionally, SFSI effects have been considered beneficial (reducing the structural response), however, recent evidence from strong earthquakes has highlighted the possibility of detrimental effects or increase in the structural response due to SFSI. This paper investigates the effects of 
SFSI on seismic response of structures through a robust Monte Carlo simulation using a wide range of realistic SFS systems and earthquake input motions in time-history analyses. The results from a total of 1.36 million analyses are used to rigorously quantify the SFSI effects on structural distortion and total horizontal displacement of the structure, and to identify conditions (system properties and earthquake motion characteristics) under which SFSI increases the structural response.

Keywords: Monte Carlo simulation, Soil-foundation-structure interaction, Equivalent linear model, Ground motion, Uncertainties

\section{INTRODUCTION}

The complexity of the seismic soil-foundation-structure interaction (SFSI) problem accompanied with the inherent uncertainty in SFS system parameters and earthquake motion characteristics has resulted in somewhat controversial interpretation of SFSI effects on the structural seismic response. Traditionally, the effects of inertial SFSI are explained by a period lengthening and increased damping of the system [1]-[3], and on this basis, it has been concluded and implemented in design codes [4],[5] that including SFSI in the analysis has a beneficial effect (or reduction) in the seismic response of structures. However, it has been also argued that the perceived beneficial role of SFSI is an oversimplification of the reality and indeed is incorrect for certain soil-structure systems and earthquake motions [6]-[10]. In addition, it has been recently shown that uncertainties arise from structural and geotechnical properties as well as input loading play an important role in performance prediction of seismically excited structures [11][13]. In particular, for systems considering soil-structure interaction, the effect of uncertainty on structural demand is even more pronounced [14]-[18]. 
In this context, the current study presents an effort for a comprehensive and systematic investigation of the effects of SFSI on the seismic response of structures. A robust statistical analysis utilizing Monte Carlo simulation was conducted using idealized soilshallow foundation-structure models following the current design practice [19]. Emphasis was given to a random selection of model parameters in a typical SFS system, such that a wide range of soil, foundation and structural properties were considered and a large number of widely varying but representative and realistic SFS models were generated. In these models, the superstructure is assumed to be a linear single-degreeof-freedom (SDOF) system with 5\% equivalent viscous damping. The reasons behind choosing a linear structural model were: (i) to follow the approach that has been adopted in building codes for developing design spectrum and defining the seismic forces acting on the structure; and (ii) to systematically address the problem and evaluate the SFSI effects, starting with a more simple linear behaviour. Note that in the second phase of this study which is reported elsewhere [20], the SFSI effects on structural nonlinear response were considered. The soil-foundation part is represented by an equivalent linear cone model [21] taking into account nonlinearity in the soil stress-strain behaviour via the equivalent linear approach [22]. It should be acknowledged that the adopted soil-foundation element does not cover the extreme material nonlinearity or geometrical nonlinearity (uplift or sliding) since they are beyond the scope of this study. The generated SFS models were excited by an ensemble of 40 earthquake ground motions recorded on stiff/soft soils to account for variability in the input motion. Thus soil, SFS system and earthquake ground motion variability are considered in this study. The paper first introduces the procedure and criteria for random generation of SFS models and then presents the results of 1.36 million analyses in terms of different 
probability levels including the median response and related dispersion. Using appropriate statistics, the probability for an increase in the structural response or detrimental effects due to SFSI effects is quantified across wide range of predominant periods and ground motion characteristics. The correlation between detrimental SFSI effects and system parameters or ground motion characteristics is also examined and quantified, and on this basis conditions for detrimental SFSI scenarios are identified.

Respecting the scope of this robust probabilistic study, the presented outcomes are limited to a SDOF system as a first step in the evaluation of the SSI effects. Also note the study does not consider extreme conditions such as those imposed by very soft (liquefiable) soils or near-fault effects on the ground motion.

\section{METHODOLOGY FOR MONTE CARLO SIMULATION}

The key objective in the Monte-Carlo simulation was to examine the seismic response of a large number of realistic SFS models when subjected to various earthquake excitations, and in this way to create basis for quantification of the SFSI effects on the structural response. Details of the adopted methodology are elaborated in the following sections.

\subsection{Adopted soil-shallow foundation-structure model}

A fairly simple SFS model was adopted for dynamic time-history analysis to represent the inertial SFSI effects on structural seismic response. The model consists of a SDOF system representing a linear superstructure and a set of equivalent linear springs and dashpots representing the soil-shallow foundation system, as shown in Figure 1. Herein, only horizontal and rocking motions of the foundation were considered and since the foundation is located on the ground surface, the horizontal and rocking degrees of 
freedom were modelled independently. As another reasonable simplification, the mass of the foundation and the mass moment of inertia of the superstructure were neglected [23].

The idealized SDOF can be interpreted as an equivalent representation of the fundamental mode of vibration of a fixed-base (FB) multi-storey structure. This SDOF structural representation is characterized by: (i) structural mass participating in the fundamental mode of vibration, $m_{\text {str }}$, (ii) structural lateral stiffness, $k_{\text {str }}$, (iii) $5 \%$ equivalent viscous structural damping, $\xi$, and (iv) effective height considered from the foundation level to the centre of the structural mass, $h_{\text {eff. }}$ The soil-foundation element is based on the cone model [21] with frequency-independent coefficients, and it represents a shallow foundation with a radius, $r$, resting on a homogeneous linear elastic halfspace. Soil material damping is also considered herein by making use of the classical Voigt model of viscoelasticity and an equivalent material damping $\xi_{0}$ which is compatible with the shear strains induced in the soil. All the coefficients of the applied soil-foundation element are summarized in Table 1.

To incorporate soil nonlinearity into the adopted soil-foundation element in a simplified manner, the conventional equivalent linear method was utilized. This approach is based on representing the soil nonlinearity by using a reduced soil modulus (secant stiffness) and an increased (equivalent) damping in accordance with the strain level in the ground induced by the earthquake. As shown in Figure 2, using the equivalent linear approach, the nonlinear stress-strain curve and corresponding hysteretic damping at a given shear strain level, $\gamma$, are represented by a degraded secant stiffness, $G_{\text {sec }}$, and an equivalent viscous damping, $\xi_{\text {eq. }}$. For a given $\gamma$, the value of $G_{s e c}$ is simply evaluated using an appropriate modulus reduction curve and a known initial shear modulus, $G_{\max }$ ( Figure 
2b). Similarly, $\xi_{\text {eq }}$ is read from the respective damping curve (Figure 2c). Through applying $G_{s e c}$ and respective shear wave velocity, $V_{s e c}=\left(G_{s e c} / \rho\right)^{1 / 2}$, and $\xi_{e q}$ in the adopted linear soil-foundation element (expressions in Table 1), the stiffness degradation and damping increase due to the soil nonlinear behaviour was incorporated.

For the purpose of this study, the response of the superstructure was examined using two response parameters: (i) structural distortion, $u$, and (ii) structural total displacement, $u_{s t r}$. Structural distortion is the horizontal displacement of the structure relative to the foundation; while structural total displacement is the sum of the horizontal foundation displacement, the structural lateral displacement due to foundation rocking and the structural distortion.

The combined effect of structural and soil parameters was also evaluated through key SFS system parameters [2],[21],[24]: (i) structural aspect ratio, $\tilde{h}=h_{\text {eff }} / r$, structureto-soil mass ratio, $\tilde{m}=m_{\text {str }} / \rho r^{3}$, and structure-to-soil stiffness ratio, $\tilde{\omega}=\omega_{\text {str }} h_{\text {eff }} / V_{s}$, (where $\omega_{\text {str }}$ is circular frequency of the fixed-base superstructure).

\subsection{Generating the random SFS models}

SFS models with randomly generated parameters were developed utilizing the following steps:

(i) Seventeen groups of SFS models were defined, each having a different predominant period for the FB superstructure, $T_{F B}$, in the range between 0.2-1.8 sec at an increment of $\Delta \mathrm{T}=0.1$ sec. This period set was selected to present superstructures with a height of 3-30 m and also satisfy the period-height relationship specified in the New Zealand Standard (NZS1170.5) [25]. The advantage of classifying the models in groups with different fundamental periods is that it allows 
to present SFSI effects on structural seismic response in a design spectrum format, similar to the approach that is followed in design spectrum analysis.

(ii) For each of these 17 groups, 1000 models were randomly generated under constraints to conform to the adopted $T_{F B}$ and to produce realistic SFS models. The selection process of the parameters for 1000 models is described below. The number of 1000 models was chosen with the intention to achieve the best fit distribution for the randomly selected parameters and increase the accuracy of the Monte-Carlo simulation [26].

Selection of uncertain soil parameters: With regard to the assumed soil-foundation element, four main soil parameters were selected as random variables: the initial soil shear wave velocity, $\left(V_{s}\right)_{0}$, the shear wave velocity degradation ratio, $\left(V_{s}\right)_{s e c} /\left(V_{s}\right)_{0}$, where $\left(V_{s}\right)_{\text {sec }}$ represents the degraded shear wave velocity, the soil mass density, $\rho$, and the Poisson's ratio, $v$. To generate random variables for each parameter, a range of realistic values was first defined for stiff/soft soils (type C and D based on USGS classification) and a uniform distribution was assigned to that range. The defined ranges of variation for all four mentioned soil parameters are summarized in Table 2. In this table, the range of $0.15-0.7$ was selected for $\left(V_{s}\right)_{s e d}\left(V_{s}\right)_{0}$ to represent the expected level of degradation for an induced shear strain of $0.01-1 \%$ in the soil medium. After defining $\rho$ and $\left(V_{s}\right)_{s e c}$, the degraded shear modulus, $G_{s e c}$, was calculated:

$$
\mathrm{G}_{\mathrm{sec}}=\rho\left(\mathrm{V}_{\mathrm{s}}\right)_{\mathrm{sec}}^{2}
$$

To define soil material damping, $\xi_{\text {eq }}$, Equation 2 was used. This equation represents the linear variation of damping between $10-25 \%$ corresponding to the velocity degradation ratio of $0.7-0.15$. 


$$
\frac{25-\xi_{\text {eq }}}{25-10}=\frac{\left(\mathrm{V}_{\mathrm{s}}\right)_{\mathrm{sec}} /\left(\mathrm{V}_{\mathrm{s}}\right)_{0}-0.15}{0.7-0.15}
$$

As an example of the adopted distributions used in the analyses, Figure 3a-c illustrates the distributions of $\left(V_{s}\right)_{s e c}, G_{s e c}$, and $\xi_{e q}$ when $\mathrm{T}_{\mathrm{FB}}=1.0$ sec.

$\underline{\text { Selection of realistic structural parameters: The first calculated structural parameter was }}$ the height of the superstructure, $h_{\text {eff. }}$ The assumed range of variation for $h_{\text {eff }}$ (summarized in Table 3) was defined based on: (i) a typical period-height relationship adopted in NZS 1170.5 [25] that can be expressed in the compact format of:

$$
0.085\left(\mathrm{~h}_{\text {eff }}\right)^{0.75} \leq \mathrm{T}_{\mathrm{FB}} \leq 0.19\left(\mathrm{~h}_{\mathrm{eff}}\right)^{0.75}
$$

and (ii) the considered limitation on the structural total height of 3-30 m. For the defined range, random variables with uniform equal likelihood were selected for each

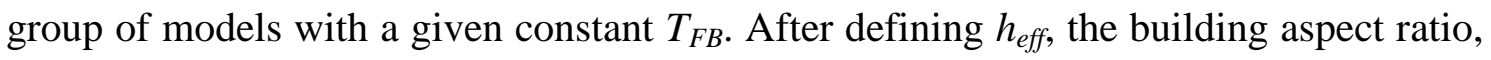
$\tilde{h}=h_{\text {eff }} / r$, was used to calculate the foundation radius, $r$. Here, it was assumed that $\tilde{h}$ varies from 1-4 for conventional building structures, and also it was assumed that $r$ is limited to the range of 2-12 m, representing structures having 1-3 bays with length of 4$8 \mathrm{~m}$ each. For each predefined value of $h_{\text {eff }}$ depending on the criteria introduced in Table 4, a random value was picked for $r$. For each model, the foundation radius along with the selected soil parameters was used to calculate the coefficients of the soil-foundation element. To define a realistic structural mass, $m_{\text {str }}$, for the defined structural and soil parameters, relative mass index $\bar{m}$ was used:

$$
\overline{\mathrm{m}}=\frac{\mathrm{m}_{\mathrm{str}}}{\mathrm{\rho r}^{2} \mathrm{~h}_{\mathrm{eff}}}
$$


Using previously defined values for $h_{\text {eff }}, r$ and $\rho$ in each group of models with constant $T_{F B}$ and considering a uniform distribution for $\bar{m}$ within the range of 0.4-0.6 (an accepted range for conventional building structures [24],[27]) random values for $m_{\text {str }}$ were selected. Following this estimation of $m_{\text {str }}$, the structural lateral stiffness, $k_{s t r}$, and the structural damping coefficient, $c_{\text {str }}$, were directly calculated:

$$
\begin{aligned}
& \mathrm{k}_{\mathrm{str}}=\frac{4 \pi^{2}}{\mathrm{~T}_{\mathrm{FB}}^{2}} \mathrm{~m}_{\mathrm{str}} \\
& \mathrm{c}_{\mathrm{str}}=2(0.05) \sqrt{\mathrm{k}_{\mathrm{str}} \mathrm{m}_{\mathrm{str}}}
\end{aligned}
$$

Figure 3d illustrates the distribution of $m_{\text {str }}$ obtained for $\mathrm{T}_{\mathrm{FB}}=1.0 \mathrm{sec}$. It is apparent from Equations 5-6 that the distributions of $k_{\text {str }}$ and $c_{s t r}$ will follow the same trend as the distribution of $m_{\text {str }}$.

Knowing all the parameters of the model, eventually the predominant period of the SFS system is calculated:

$$
\mathrm{T}_{\mathrm{SFS}}=\mathrm{T}_{\mathrm{FB}} \sqrt{1+\frac{\mathrm{k}_{\mathrm{str}}}{\mathrm{k}_{0}}+\frac{\mathrm{k}_{\mathrm{str}} \mathrm{h}_{\mathrm{eff}}^{2}}{\mathrm{k}_{\varphi}}}
$$

The described procedure for selection of uncertain soil and structural parameters are schematically illustrated in Figure 4.

\subsection{Performing the Analyses}

To cover the aleatory uncertainties caused by record-to-record variability, all the developed SFS models along with their corresponding FB models were analysed using a suite of 40 earthquake ground motions. Since kinematic interaction is zero for shallow 
foundation [1],[27], the acceleration time-history of the recorded earthquakes on freefield was directly used as an input at the foundation level.

Applied input earthquake ground motions: An ensemble of 40 ground motions recorded on stiff/soft soils (type C and D based on USGS classification) was used in the analyses (Table A.1). All the selected records are from earthquakes with magnitude of 6.5-7.5 and have a closest source-to-site distance in the range from 15-40 km. In addition, the records have peak ground accelerations (PGA) greater than 0.1g. Normalized elastic acceleration response spectra (for 5\% damping) of the selected earthquake records are shown in Figure 5.

\subsection{Representation of the structural response}

Since the considered analyses are equivalent linear, only the maximum values for $u$ (structural distortion) and $u_{\text {str }}$ (structural total displacement) resulting from the timehistory analyses are discussed. The resulted values for the response of SFS models are presented in a normalized form as a ratio with respect to the results obtained from the corresponding FB models for the same earthquake ground motion. Based on these definitions, SFSI is recognized to have detrimental effects in terms of structural distortion when $u_{S F S} / u_{F B}>1.0$ and in terms of structural total displacement when $\left(u_{s t r}\right)_{S F S}\left(u_{s t r}\right)_{F B}>1.0$

\subsection{Presentation of results from analyses}

To characterize the central tendency of the seismic response of the SFS system, the median value is selected as the statistical measure. In addition, the level of dispersion existing in the resulted data in each group of models is quantified in terms of the coefficient of variation (COV), which is the ratio of the standard deviation to the mean. 
Two alternative approaches are also used to distinguish between the dispersions due to uncertainty in system parameters (SPs) and record-to-record (RTR) variability. These two approaches are explained below:

1- $\operatorname{COV}[E(X \mid S P):$ A measure of dispersion in the structural response parameter $(X)$ due to uncertainty in SPs. To evaluate it, the mean of $40 \mathrm{X}$ values, denoted by $\mathrm{E}(\mathrm{X} \mid \mathrm{SP})$ and resulting from 40 time-history analyses using different input motions, was calculated first for each of the 1000 adopted models. Afterwards, the COV of these 1000 calculated mean values is evaluated.

2- $\operatorname{COV}[E(X \mid E Q)]:$ A measure of dispersion in the structural response parameter $(X)$ due to RTR variability. To calculate it, the mean value of $1000 \mathrm{X}$ values, denoted by $\mathrm{E}(\mathrm{X} \mid \mathrm{EQ})$ and resulting from 1000 time-history analyses over 1000 adopted models, was calculated first for each of the 40 ground motions. Afterwards, the COV of these 40 calculated mean values is calculated.

\section{RESULTS AND DISCUSSION}

In this Monte Carlo simulation, the wide range of selected models $(2 \times 17000$ SFS and FB models) and ground motions (40 earthquakes) yielded 1.36 million analyses in total. It thus allows for a comprehensive statistical study of the effects of foundation flexibility on the structural seismic response. The outcomes from the analyses are detailed in four sections: (i) quantification of the SFSI effects on structural seismic response; (ii) evaluation of the risk for having detrimental SFSI effects on structural seismic response (or DSFSI) and quantification of the corresponding increase in the structural response; (iii) identification of DSFSI scenarios in terms of earthquake motion characteristics; and (iv) correlation between the likelihood of DSFSI effects and key SFS system characteristics. 


\subsection{Quantification of the SFSI effects on structural seismic response}

Structural Distortion: Figure 6 displays the median and the maximum values of structural distortion modification factor $\left(u_{S F S} / u_{F B}\right)$ in a design spectrum format. At each specific period, the resulting responses from 40,000 different scenarios (40 earthquakes and 1000 models) are presented. Clearly, the median response for all considered scenarios is less than unity, indicating that in $50 \%$ of all cases (or on average), SFSI decreases the deformation of the structure or the drift level. The median values are in the range of 0.7-0.9 depending on the value of $T_{F B}$. However, it is evident that for some cases SFSI may increase the structural distortion and nearly double the response of the FB model.

The reliability of the measured median values was examined by evaluating the coefficient of variation, $\operatorname{COV}(\mathrm{u})$. As shown in Figure 7, the dispersion in the data is in the acceptable range. Furthermore, comparing the results for $\operatorname{COV}[\mathrm{E}(\mathrm{u} \mid \mathrm{SP})]$ and $\operatorname{COV}[\mathrm{E}(\mathrm{u} \mid \mathrm{EQ})]$ reveals that the contribution of uncertainty in the SPs to the dispersion in $u_{S F S} / u_{F B}$ is greater than the contribution of RTR variability. This suggests that SFSI effects on structural distortion are more sensitive to the modelling parameters of the SFS system than to the input ground motion characteristics, at least within the ground motion constraints adopted in this study.

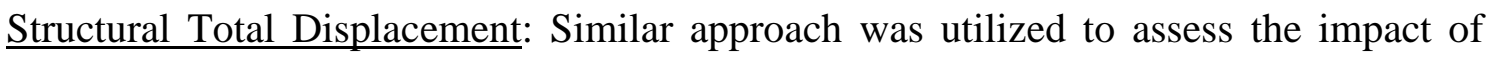
foundation flexibility on the structural total displacement. The median and the maximum values of structural total displacement modification factor $\left(\left(u_{s t r}\right)_{S F S} /\left(u_{s t r}\right)_{F B}\right)$ are shown in Figure 8. The median values, except for stiff structures $\left(\mathrm{T}_{\mathrm{FB}}<0.5\right)$, are almost around unity, indicating that consideration of foundation flexibility, in $50 \%$ of the cases, does not cause a significant change in the total displacement of the structure. 
For stiff structures, however, the median response increases up to $10 \%$ relative to the FB response. The plot clearly shows that consideration of SFSI effects may increase the structural total displacement from 5 to 15 times.

The measured dispersions in $u_{\text {str }}$ are illustrated in Figure 9. The value of $\operatorname{COV}\left(\mathrm{u}_{\mathrm{str}}\right)$ is in the range which results in the reliable measured median values. Conversely to what is seen in Figure 7, the contribution of uncertainty in the SPs to the dispersion in $\left(u_{s t r}\right)_{S F S} /\left(u_{S t r}\right)_{F B}$ for structures with $\mathrm{T}_{\mathrm{FB}}>0.4 \mathrm{sec}$ is less than the contribution of RTR variability. Thus, the SFSI effects on structural total displacement are more sensitive to the input ground motions.

\subsection{Evaluation of the risk for DSFSI scenarios}

To quantify the SFSI amplification effect on the response of the superstructure, two main aspects should be considered: (i) the probability to cause amplification in the response of the superstructure as compared to that of a fixed-base model; and then, if this is the case, (ii) the level of increase in the response due to SFSI effects.

Structural Distortion: Figure 10a presents with the solid line the probability of the cases in which $u_{S F S} u_{F B}>1.0$ across the range of considered periods. This probability is denoted by $\operatorname{Pr}\left[\mathrm{u}_{\mathrm{SFS}} / \mathrm{u}_{\mathrm{FB}}>1.0\right]$. Clearly, the probability of amplification in the response due to SFSI effects is between $20 \%$ and $30 \%$ for stiff structures $\left(\mathrm{T}_{\mathrm{FB}}<0.5 \mathrm{sec}\right.$ ) and between $10 \%$ and $15 \%$ for more flexible structures. For each probability, Figure $10 \mathrm{a}$ also illustrates the median values of the percentage increase, denoted by Med[PI], which vary in the range of $2-9 \%$. Considering the observed probability of amplification along with the percentage increase, it can be concluded that consideration of SFSI in the analysis may increase the stress and deformation within the superstructure, but the total 
risk of an increase in the level of expected damage is relatively low. However, as shown in Figure 6, there is always a possibility of encountering extreme cases where the amplification in the response is almost $100 \%$. To better quantify the probability for an increase in the structural distortion due to SFSI effects, Figure 10b indicates the probability for amplification of the response of more than $10 \%$ and more than $25 \%$ respectively, relative to the fixed-base response. This figure shows that there is a probability of $2-10 \%$ the structural distortion to be increased due to SFSI effects by more than $10 \%$ and a probability of less than $2 \%$ the response to be amplified by more than $25 \%$.

Structural Total Displacement: In terms of structural total displacement, Figure 11a shows the probability of the cases in which $\left(u_{s t r}\right)_{S F S} /\left(u_{s t r}\right)_{F B}>1.0$. This probability is denoted by $\operatorname{Pr}\left[\left(\mathrm{u}_{\mathrm{str}}\right)_{\mathrm{SFS}} /\left(\mathrm{u}_{\mathrm{str}}\right)_{\mathrm{FB}}>1.0\right]$. For stiffer structures $\left(\mathrm{T}_{\mathrm{FB}}<0.5 \mathrm{sec}\right)$, the probability of having an amplified response due to SFSI consideration is in the range of $50-80 \%$ and this probability reduces to $40-50 \%$ for more flexible, longer period, structures. The median values of the corresponding percentage increase are around 8-18\%. However, as shown in Figure 8, in extreme cases, foundation flexibility may cause an increase in the structural horizontal displacement by a factor of 15 . This amplification is important if structural pounding is of concern or yielding of foundation soil is expected. Figure 11b shows that there is a probability of $20-50 \%$ for at least $10 \%$ increase (or greater) in the total displacement due to SFSI effects, while there is about $10-30 \%$ probability for amplification of this displacement of over $25 \%$.

\subsection{Identification of DSFSI scenarios in terms earthquake motion properties}

As demonstrated in Sections 3.1 and 3.2, detrimental SFSI effects are expected to occur for certain soil-structure systems and earthquake excitations. In this section, the relation 
between the characteristics of the SFS model and the earthquake motion that may cause an increase in the structural distortion (or strength demand in linear analysis) is investigated. To illustrate the role of the input motion properties in stimulating DSFSI scenarios, the histogram of earthquake motions causing detrimental SFSI effects for models with $\mathrm{T}_{\mathrm{FB}}=1.0 \mathrm{sec}$ is shown in Figure 12, as an example. Clearly, the increase in the structural distortion depends on the particular ground motion used and is very pronounced for some earthquakes while completely absent for others. For instance, EQ No. 23 causes detrimental effects for more than 400 SFS models while EQ No. 2 causes no detrimental effects at all.

To clarify this outcome, Figures 13a and 13b show with the solid line the acceleration response spectrum of the earthquake (input) motion, $\left(S_{a}\right)_{E Q}$, along with the computed maximum acceleration response of the FB model, $\left(a_{t}\right)_{F B}$ (shown with the bold symbol), and SFS models, $\left(a_{t}\right)_{S F S}$ (open symbols), for systems with $\mathrm{T}_{\mathrm{FB}}=1.0$ sec subjected to EQ No. 23 (Figure 13a) and EQ No. 2 (Figure 13b) respectively. As shown in the figure, the response pattern of the SFS models closely follows the shape of the response spectrum of the earthquake motion, though some deviation around the spectrum line is apparent. This response feature together with the fact that foundation flexibility increases the period of the system $\left(\mathrm{T}_{\mathrm{SFS}}>\mathrm{T}_{\mathrm{FB}}\right.$, e.g. Equation 7) leads to a simple rule for identification of the SFSI effects: SFSI will result in detrimental effects or increase in the structural response relative to that of the fixed-base model if the response spectrum of the input earthquake motion has an ascending branch (Figure 13a) in the range of periods slightly greater than $\mathrm{T}_{\mathrm{FB}}$. On the other hand, if the spectrum has a descending branch in this range of periods, then SFSI effects will be beneficial and will cause a decrease in the structural response (Figure 13b). 


\subsection{Quantification of DSFSI scenarios for variation of SFS system parameters}

The impact of key SFS system parameters, $\tilde{h}, \tilde{m}, \tilde{\omega}$, on SFSI effects and the correlation of these parameters with the DSFS scenarios is investigated herein. The conditional probability of having a DSFSI scenario given a system parameter $\mathrm{X}$, denoted by $\operatorname{Pr}\left[\mathrm{DSFSI} \mid \mathrm{X}=\mathrm{x}_{\mathrm{i}}\right]$, was calculated through the variation range of $\mathrm{X}$ :

$$
\operatorname{Pr}\left[\text { DSFSI } \mid \mathrm{X}=\mathrm{x}_{\mathrm{i}}\right]=\frac{\operatorname{Pr}\left[\mathrm{X}=\mathrm{x}_{\mathrm{i}} \mid \mathrm{DSFSI}\right] \operatorname{Pr}[\mathrm{DSFSI}]}{\operatorname{Pr}\left[\mathrm{X}=\mathrm{x}_{\mathrm{i}}\right]}=\frac{\mathrm{N}_{1}}{\mathrm{M}_{1}}
$$

where $\mathrm{N}_{1}$ is number of models with DSFSI effect and $\mathrm{X}=\mathrm{X}_{\mathrm{i}}$, and $\mathrm{M}_{1}$ is the number of all models with $\mathrm{X}=\mathrm{x}_{\mathrm{i}}$. In addition to the calculated conditional probability, the median value of the percentage increase for each considered system key parameter, denoted by $\operatorname{Med}\left[\mathrm{PI} \mid \mathrm{X}=\mathrm{X}_{\mathrm{i}}\right]$, is also presented. The results are illustrated in Figures $14-15$ and are summarized below.

Figures $14 \mathrm{a}$ and $14 \mathrm{~b}$ show the results for $\tilde{h}$, for the structural distortion and total displacement respectively. Clearly, an increase in $\tilde{h}$ reduces the probability for detrimental effects or DSFSI scenarios (as shown by the solid line). The median percentage increase in the response increases with $\tilde{h}$ and the rate of increase is higher for the total displacement (Figure 14b). Similar trend and values as those shown in Figure 14 were obtained for $\tilde{m}$.

The influence of $\tilde{\omega}$ on DSFSI scenarios is presented in Figure 15a and 15b. In this case, the observed trends for the structural distortion and total displacement are completely different. The probability of DSFSI in terms of structural distortion $\left(u_{S F S} / u_{F B}>1.0\right)$ sharply decreases with the increase in $\tilde{\omega}$, such that for values of $\tilde{\omega}>2.5$ the risk of having DSFSI could be ignored. The median value of increase in structural distortion is 
about $10 \%$ for $\tilde{\omega}<4.8$ and $2-6 \%$ for $\tilde{\omega}>4.8$ (Figure 15a). For the total displacement, there is no strong correlation between the probability for DSFS scenarios and $\tilde{\omega}$, however, there is a clear trend for an increase in the amplification of the response with $\widetilde{\omega}$, and this increase reaches $60-70 \%$ at high $\tilde{\omega}$ values (Figure $15 \mathrm{~b}$ ).

\section{CONCLUSION}

A comprehensive Monte Carlo simulation using an established rheological soil-shallow foundation-structure (SFS) model was carried out to systematically investigate the effects of SFS interaction on the seismic response of structures. In the analyses, the superstructure was represented by a linear single-degree-of-freedom (SDOF) system while the nonlinear stress-strain relationship of the soil was approximated by an equivalent linear model. The process of random generation of models was designed to cover a wide range of soil, foundation and superstructure properties and was constrained to yield realistic and representative soil-foundation-structure systems. To account for variability in the earthquake excitation, 40 different ground motions were used as input in the time-history analyses resulting in a comprehensive set of 1.36 million simulations. The key findings from these analyses can be summarized as follows:

1) In median terms, the consideration of foundation flexibility in the seismic analysis reduces the structural distortion by a factor $\left(u_{S F S} / u_{F B}\right)$ of $0.7-0.9$ depending on the fixed-base period of the superstructure. The median value of the total displacement factor $\left[\left(u_{s t r}\right)_{S F S} /\left(u_{s t r}\right)_{F B}\right]$ is in the range between 0.95 and 1.1 indicating that on average SFSI increases the total horizontal displacement of the superstructure.

2) There is $10-30 \%$ likelihood of amplification in the structural distortion due to SFSI effects with the median percentage increase of $2-9 \%$ and a potential 
maximum amplification of nearly 100\%. The probability for amplification of the response for more than $10 \%$ is $2-10 \%$, while the probability for amplification of over $25 \%$ is less than $2 \%$.

3) There is $10-30 \%$ probability for amplification of the total displacement of the superstructure due to SFSI effects of over 25\%. In the extreme case, consideration of foundation flexibility may result in fifteen times greater total (horizontal) displacement of the superstructure as compared to that of the fixed base structure.

4) There is a clear link between the increase in the structural response due to SFSI effects and the response spectrum characteristics of the earthquake motion. Detrimental SFSI effects or increase in the structural distortion occur for ground motions having an ascending branch in the response spectrum in the range of periods slightly greater than $T_{F B}$.

5) An increase in the value of the aspect ratio $(\tilde{h})$ or the mass ratio $(\tilde{m})$ reduces the probability for detrimental soil-foundation-structure interaction (DSFSI) scenarios but raises the median increase in the structural response. Both these trends are well defined but of relatively small magnitude.

6) There is strong correlation between the detrimental SFSI effects and the stiffness ratio, $\widetilde{\omega}$. The probability of DSFSI scenarios in terms of structural distortion decreases sharply with the increase of $\tilde{\omega}$, such that for $\tilde{\omega}>2.5$ this probability is nearly zero. Conversely, the median amplification of the total structural displacement steadily increases with $\tilde{\omega}$ up to values of about $60-70 \%$ for $\tilde{\omega}>4$.

\section{REFERENCES}

[1] Jennings PC, Beilak J. Dynamics of building-soil interaction. B Seismol Soc Am 1973; 63(1):9-48. 
[2] Veletsos AS, Meek JW. Dynamic behaviour of building-foundation systems. Earthq Eng Struct Dyn 1974; 3:121-38.

[3] Veletsos AS, Nair VVD. Seismic interaction of structures on hysteresis foundations. J Struct DivASCE 1975; 101:109-129.

[4] Applied Technology Council. Tentative Provisions for the Development of Seismic Regulations for Buildings; ATC-3-06: California, 1984.

[5] FEMA 440. Recommended Improvements of Nonlinear Static Seismic Analysis Procedures. Applied Technology Council: California, 2005.

[6] Beilak J. Dynamic behaviour of structures with embedded foundations. Earthq Eng Struct Dyn 1975; 3:259-274.

[7] Dutta SC, Bhattacharya K, Roy R. Response of low-rise buildings under seismic ground excitation incorporating soil-structure interaction. Soil Dyn and Earthq Eng 2004; 24:893-914.

[8] Gazetas G, Mylonakis G. Seismic soil-structure interaction: new evidence and emerging issues. Geotechnical Earthquake Engineering and Soil Dynamics 3: proceedings of speciality conference. American Society of Civil Engineers 1998; 1119-74.

[9] Mylonakis G, Gazetas G. Seismic soil-structure interaction: beneficial or detrimental. J Earthq Eng 2000; 4(3): 227-301.

[10] Gazetas G, Mylonakis G. Soil-structure interaction effects on elastic and inelastic structures. Proceedings of the fourth international Conference on recent advances in Geotechnical Earthquake Engineering and Soil Dynamics. San Diego, California, March 26-31, 2001.

[11] Mehanny SSF, Ayou AS. Variability in inelastic displacement demands: Uncertainty in system parameters versus randomness in ground records. Eng Struct 2008; 30(4): 1002-1013.

[12] Chaudhuri A, Chakraborty S. Sensitivity evaluation in seismic reliability analysis of structures. Comput. Methods Appl. Mech. Engrg. 2004; 193: 59-68.

[13] Marano GC, Trentadue F, Morrone E, Amara L. Sensitivity analysis of optimum stochastic nonstationary response spectra under uncertain soil parameters. Soil Dyn and Earthq Eng 2008; 28: 1078-1093.

[14] Barcena A, Esteva L. (2007). Influence of dynamic soil-structure interaction on the nonlinear response and seismic reliability of multistorey systems. Earthq Eng Struct Dyn 2007; 36(3): 327-346.

[15] Jin S, Lutes LD, Sarkani S. (2000). Response variability for a structure with soil-structure interactions and uncertain soil properties. Prob Eng Mech 2000; 15(2): 175-183.

[16] Lutes LD, Sarkani S, Jin S. Response variability of an SSI system with uncertain structural and soil properties. Eng Struc 2000, 22(6): 605-620.

[17] Raychowdhury P. Effect of soil parameter uncertainty on seismic demand of low-rise steel buildings on dense silty sand. Soil Dyn and Earthq Eng 2009; 29(10): 1367-1378.

[18] Moghaddasi M, Cubrinovski M, Pampanin S, Carr A, Chase JG. Monte Carlo Simulation of SSI Effects Using Simple Rheological Soil Model. 2009 NZSEE Conference. Christchurch, New Zealand: 3-5 April 2009.

[19] Stewart JP, et al. Revisions to soil-structure interaction procedures in NEHRP design provisions. Earthq Spectra 2003; 19(3): 677-96.

[20] Moghaddasi M, Cubrinovski M, Pampanin S, Carr A, Chase JG. Probabilistic evaluation of soilfoundation-structure interaction effects on seismic structure response. Earthq Eng Struct Dyn 2010. DOI: 10.1002/eqe. 1011.

[21] Wolf JP. Foundation Vibration Analysis Using Simple Physical Model, Englewood Cliffs, NJ: Prentice-Hall, 1994.

[22] Seed HB, Idriss IM. Soil moduli and damping factors for dynamic response analysis. Report EERC 70-10. Earthquake Engineering Research Centre, 1970.

[23] Beilak J. Dynamic response of nonlinear building foundation systems. Earthq Eng Struct Dyn 1978; 7:17-30.

[24] Nakhaei M, Ghanad MA. The Effect of Soil-Structure Interaction on Damage Index of Building. Eng Struct 2008; 30:1491-99.

[25] NZS 1170.5: Structural Design Actions. Part 5: Earthquake Actions. New Zealand; 2004.

[26] Fishman, G. S. Monte Carlo: Concepts, Algorithms, and Applications. New York, Springer-Verlag; 1995.

[27] Stewart JP, Fenves GL, Seed RB. Seismic soil-structure interaction in buildings: I: analytical aspects. J Geotech Geoenviron 1999; 125(1) 26-37. 


\section{APPENDIX}

Table A. 1. Earthquake ground motions recorded on soil type C/D (USGS categorization ${ }^{1}$ ) used as input motions in the analyses

\begin{tabular}{|c|c|c|c|c|c|c|c|c|c|c|}
\hline ID & Event & Year & Station & M & Soil & $\mathrm{R}(\mathrm{km})$ & PGA (g) & $\begin{array}{l}\mathrm{PGV} \\
(\mathrm{cm} / \mathrm{s})\end{array}$ & $\begin{array}{l}\text { PGD } \\
(\mathrm{cm})\end{array}$ & $\mathrm{Ta}(\mathrm{s})$ \\
\hline 1 & \multirow[t]{5}{*}{ Chi-Chi, Taiwan } & \multirow[t]{5}{*}{1999} & CHY010/E & \multirow[t]{5}{*}{7.6} & $\mathrm{C}$ & 25.4 & 0.23 & 21.9 & 11.1 & 0.27 \\
\hline 2 & & & CHY034/N & & $\mathrm{C}$ & 20.2 & 0.31 & 48.5 & 16.5 & 0.94 \\
\hline 3 & & & CHY035/W & & $\mathrm{C}$ & 18.2 & 0.25 & 45.6 & 12.0 & 0.87 \\
\hline 4 & & & CHY036/W & & $\mathrm{C}$ & 20.4 & 0.29 & 38.9 & 21.2 & 0.53 \\
\hline 5 & & & $\mathrm{NST} / \mathrm{N}$ & & $\mathrm{C}$ & 37 & 0.39 & 26.9 & 16.1 & 0.17 \\
\hline 6 & \multirow{2}{*}{$\begin{array}{l}\text { Kocaeli, Turkey } \\
\text { Landers }\end{array}$} & \multirow{2}{*}{$\begin{array}{l}1999 \\
1992\end{array}$} & Iznik/IZN090 & \multirow{2}{*}{$\begin{array}{l}7.4 \\
7.3\end{array}$} & $\mathrm{C}$ & 31.8 & 0.14 & 28.8 & 17.4 & 1.17 \\
\hline 7 & & & 22074 Yermo Fire Station /YER270 & & $\mathrm{C}$ & 24.9 & 0.25 & 51.5 & 43.8 & 0.68 \\
\hline 8 & \multirow[t]{8}{*}{ Loma Prieta } & \multirow[t]{8}{*}{1989} & 57066 Agnews State Hospital/AGW000 & \multirow[t]{8}{*}{6.9} & $\mathrm{C}$ & 28.2 & 0.17 & 26.0 & 12.6 & 0.26 \\
\hline 9 & & & 57191 Halls Valley/HVR000 & & $\mathrm{C}$ & 31.6 & 0.13 & 15.4 & 3.3 & 0.78 \\
\hline 10 & & & 1028 Hollister City Hall/HCH090 & & $\mathrm{C}$ & 28.2 & 0.25 & 38.5 & 17.8 & 0.82 \\
\hline 11 & & & 57382 Gilroy Array \#4/G04000 & & $\mathrm{C}$ & 16.1 & 0.42 & 38.8 & 7.1 & 0.44 \\
\hline 12 & & & 57425 Gilroy Array \#7/GMR090 & & $\mathrm{C}$ & 24.2 & 0.32 & 16.6 & 3.3 & 0.44 \\
\hline 13 & & & 1601 Palo Alto - SLAC Lab/SLC360 & & $\mathrm{C}$ & 36.3 & 0.28 & 29.3 & 9.7 & 0.31 \\
\hline 14 & & & 47179 Salinas - John \& Work/SJW250 & & $\mathrm{C}$ & 32.6 & 0.11 & 15.7 & 7.9 & 0.22 \\
\hline 15 & & & 1695 Sunnyvale - Colton Ave/ SVL360 & & $\mathrm{C}$ & 28.8 & 0.21 & 36.0 & 16.9 & 0.21 \\
\hline 16 & \multirow[t]{6}{*}{ Northridge } & \multirow[t]{6}{*}{1994} & 25282 Camarillo/CMR180 & \multirow[t]{6}{*}{6.7} & $\mathrm{C}$ & 36.5 & 0.13 & 10.9 & 3.5 & 0.53 \\
\hline 17 & & & $\begin{array}{l}90053 \text { Canoga Park - Topanga } \\
\text { Can/CNP196 }\end{array}$ & & $\mathrm{C}$ & 15.8 & 0.42 & 60.8 & 20.2 & 0.6 \\
\hline 18 & & & 24575 Elizabeth Lake/ELI090 & & $\mathrm{C}$ & 37.2 & 0.16 & 7.3 & 2.7 & 0.26 \\
\hline 19 & & & 90063 Glendale - Las Palmas/GLP177 & & $\mathrm{C}$ & 25.4 & 0.36 & 12.3 & 1.9 & 0.2 \\
\hline 20 & & & 90054 LA - Centinela St/CEN155 & & $\mathrm{C}$ & 30.9 & 0.47 & 19.3 & 3.5 & 0.16 \\
\hline 21 & & & 90060 La Crescenta - New York/NYA090 & & $\mathrm{C}$ & 22.3 & 0.18 & 12.5 & 1.1 & 0.46 \\
\hline
\end{tabular}




\begin{tabular}{|c|c|c|c|c|c|c|c|c|c|c|}
\hline 22 & & & 90025 LA - E Vernon Ave/VER180 & & $\mathrm{C}$ & 39.3 & 0.15 & 10.1 & 1.8 & 0.19 \\
\hline 23 & & & 90034 LA - Fletcher Dr/FLE234 & & $\mathrm{C}$ & 29.5 & 0.24 & 26.2 & 3.6 & 0.51 \\
\hline 24 & & & 24303 LA - Hollywood Stor FF/HOL360 & & $\mathrm{C}$ & 25.5 & 0.36 & 27.5 & 3.0 & 0.18 \\
\hline 25 & & & 90016 LA - N Faring Rd/FAR000 & & $\mathrm{C}$ & 23.9 & 0.27 & 15.8 & 3.3 & 0.63 \\
\hline 26 & & & 24612 LA - Pico \& Sentous/PIC180 & & $\mathrm{C}$ & 32.7 & 0.19 & 14.3 & 2.4 & 0.78 \\
\hline 27 & & & 90022 LA - S Grand Ave/GR2090 & & $\mathrm{C}$ & 36.9 & 0.29 & 17.9 & 2.4 & 0.29 \\
\hline 28 & & & 90096 LA - S. Vermont Ave/VRM000 & & $\mathrm{C}$ & 34.7 & 0.16 & 10.7 & 1.8 & 0.45 \\
\hline 29 & & & 90091 LA - Saturn St/STN020 & & $\mathrm{C}$ & 30 & 0.47 & 34.6 & 6.6 & 0.15 \\
\hline 30 & & & 24055 Leona Valley \#5 - Ritter/LV5000 & & $\mathrm{C}$ & 38.3 & 0.15 & 14.9 & 2.4 & 0.22 \\
\hline 31 & & & 24309 Leona Valley \#6/LV6090 & & $\mathrm{C}$ & 38.5 & 0.18 & 14.4 & 2.1 & 0.2 \\
\hline 32 & \multirow{4}{*}{ Superstition Hills (B) } & \multirow{4}{*}{1987} & $\begin{array}{l}90095 \text { Pasadena - N Sierra } \\
\text { Madre/SMV180 }\end{array}$ & \multirow{3}{*}{6.7} & $\mathrm{C}$ & 39.2 & 0.25 & 12.3 & 1.1 & 0.41 \\
\hline 33 & & & 5060 Brawley/B-BRA225 & & $\mathrm{C}$ & 18.2 & 0.16 & 13.9 & 5.4 & 0.1 \\
\hline 34 & & & 5061 Calipatria Fire Station/B-CAL315 & & $\mathrm{C}$ & 28.3 & 0.25 & 14.6 & 3.1 & 0.16 \\
\hline 35 & & & 5052 Plaster City/B-PLS135 & \multirow[b]{2}{*}{7.6} & $\mathrm{C}$ & 21 & 0.19 & 20.6 & 5.4 & 0.42 \\
\hline 36 & \multirow[t]{2}{*}{ Chi-Chi, Taiwan } & \multirow[t]{2}{*}{1999} & CHY041/W & & $\mathrm{D}$ & 26 & 0.3 & 20.4 & 8.6 & 0.26 \\
\hline 37 & & & TCU040/W & \multirow[b]{2}{*}{6.9} & $\mathrm{D}$ & 21 & 0.15 & 50.9 & 57.4 & 0.39 \\
\hline 38 & \multirow[t]{2}{*}{ Kobe } & \multirow[t]{2}{*}{1995} & 0 Kakogawa/KAK090 & & $\mathrm{D}$ & 26.4 & 0.35 & 27.6 & 9.6 & 0.16 \\
\hline 39 & & & 0 Shin-Osaka/SHI000 & \multirow[b]{2}{*}{6.7} & $\mathrm{D}$ & 15.5 & 0.24 & 37.8 & 8.5 & 0.66 \\
\hline 40 & Superstition Hills (B) & 1987 & $\begin{array}{l}5062 \text { Salton Sea Wildlife Refuge/B- } \\
\text { WLF315 }\end{array}$ & & $\mathrm{D}$ & 27.1 & 0.17 & 18.3 & 4.3 & 0.26 \\
\hline
\end{tabular}

- ${ }^{1}$ USGS site classification is based on average shear wave velocity to a depth of $30 \mathrm{~m}$ in which for soil type C: Vs = $180-360 \mathrm{~m} / \mathrm{sec}$ and for soil type D: Vs $\leq 180 \mathrm{~m} / \mathrm{sec}$ 


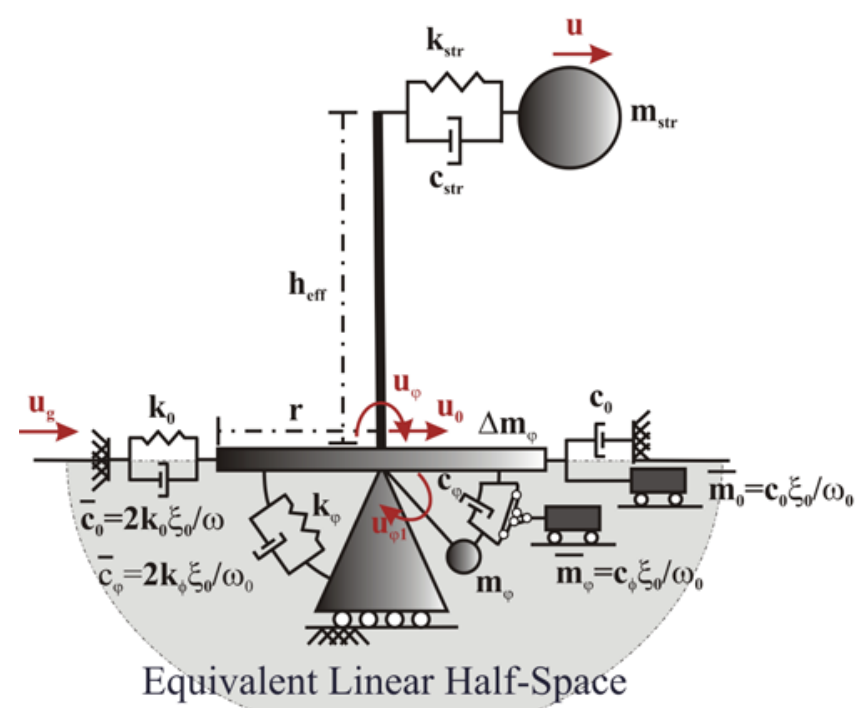

Figure 1. Coupled dynamic soil-shallow foundation-structure model for horizontal and rocking motions (the expressions for model parameters are defined in Table 1) 


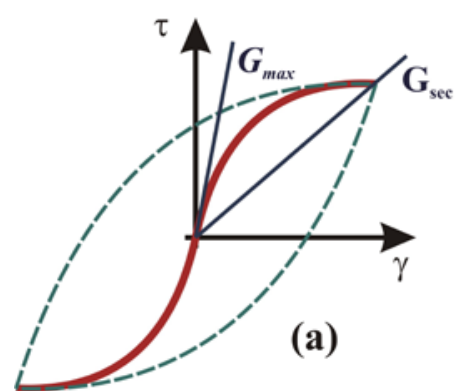

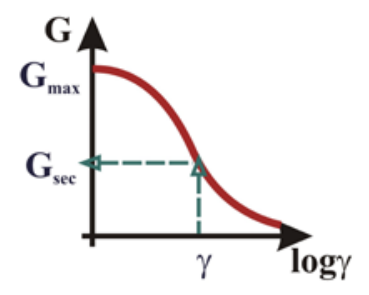

(b)

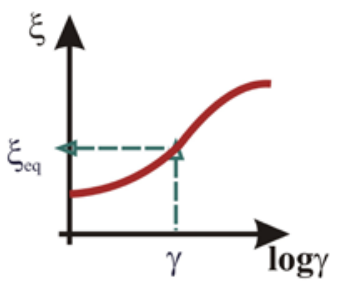

(c)

Figure 2. Equivalent linear idealization of non-linear soil behaviour: (a) shear stressstrain behaviour, (b) secant modulus vs. shear strain and (c) equivalent damping vs. shear strain 
(a)

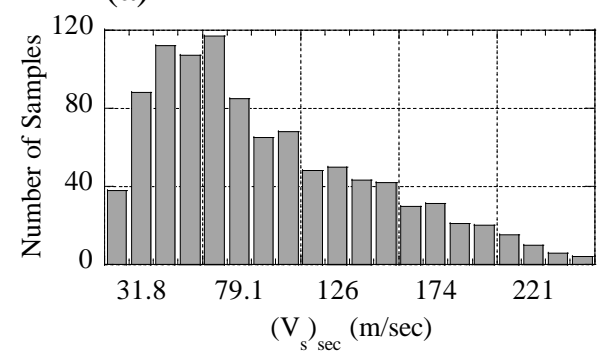

(c)

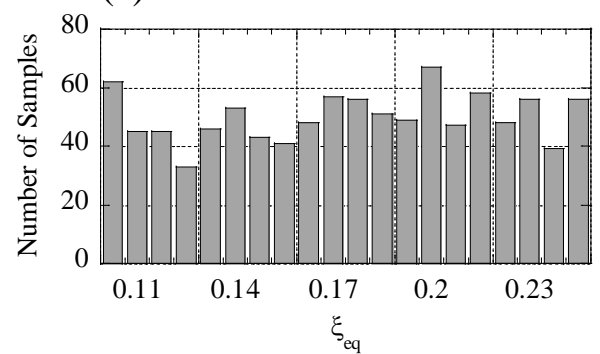

(b)

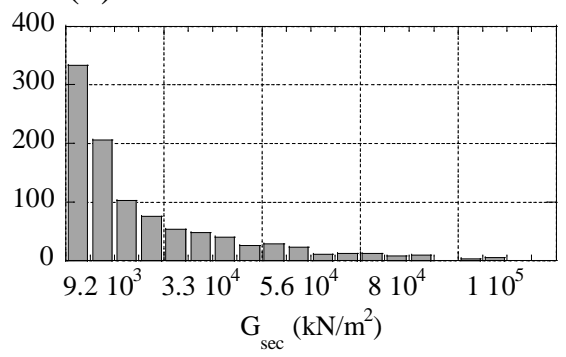

(d)

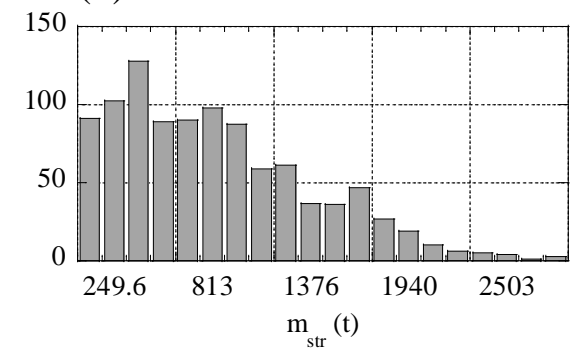

Figure 3. Distribution of: (a) degraded shear wave velocity, (b) degraded shear modulus (c) soil material damping and (d) structural mass for $\mathrm{T}_{\mathrm{FB}}=1.0 \mathrm{sec}$ 


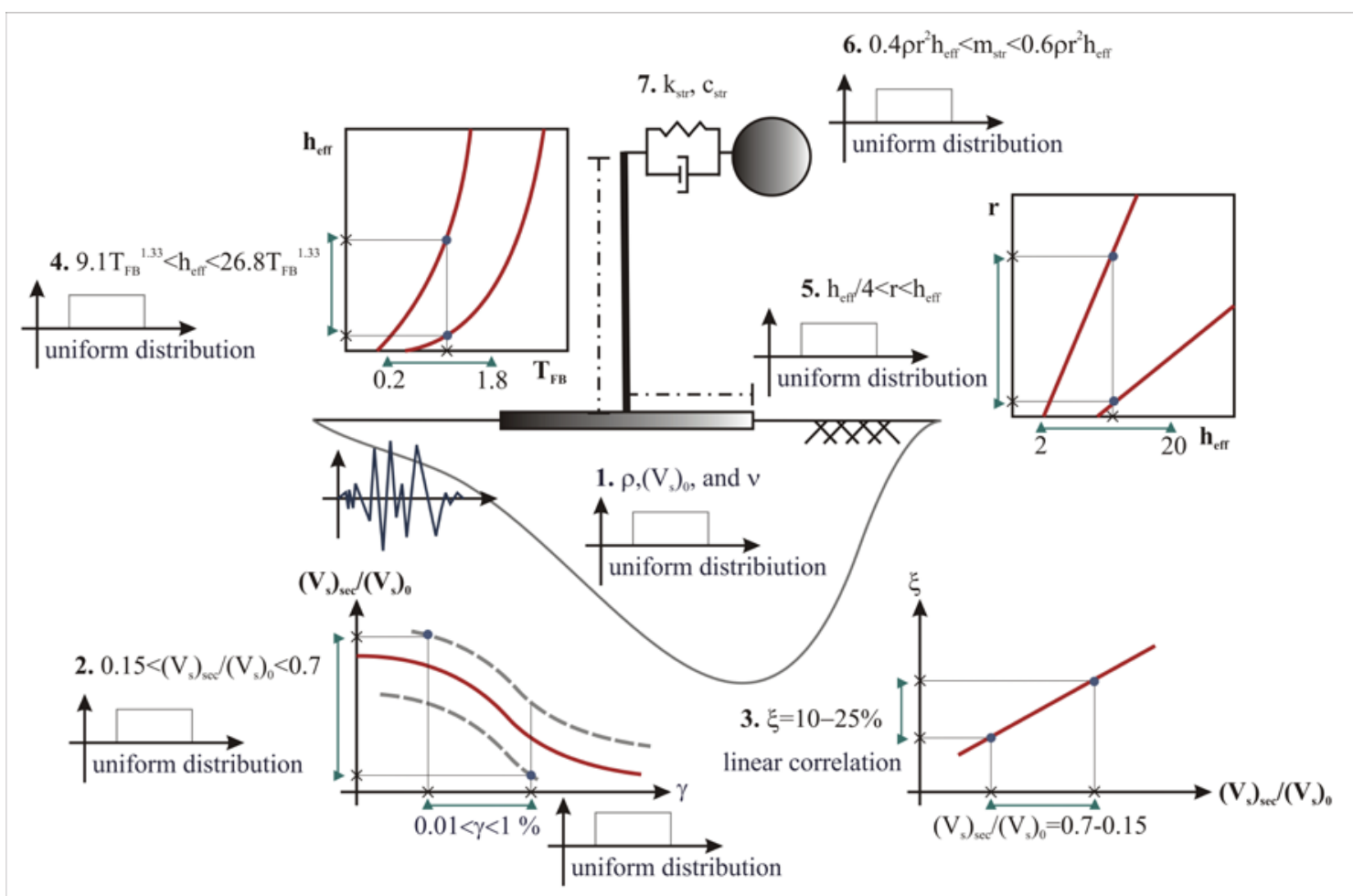

Figure 4. Schematic illustration for random generation of model parameters 


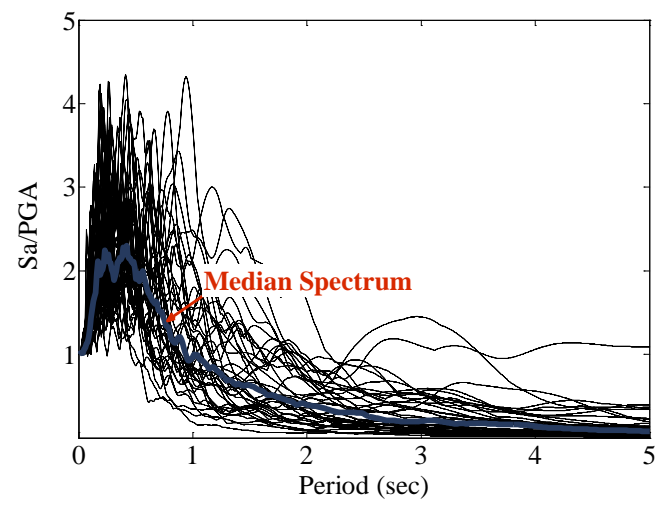

Figure 5. Normalized elastic acceleration response spectra (5\% damping) of the selected earthquake ground motions to PGA=1.0g 


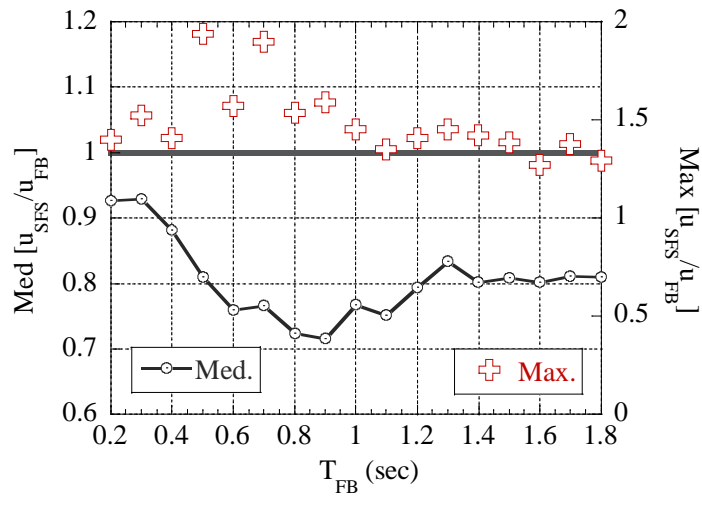

Figure 6. Structural distortion modification spectrum in terms of median and maximum values 


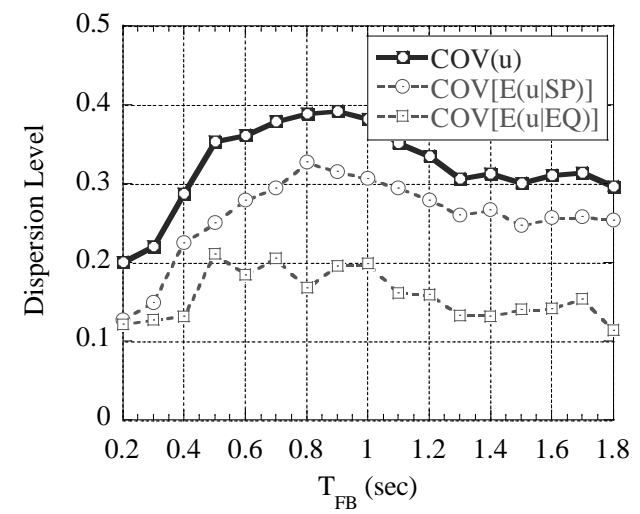

Figure 7. Dispersions in structural distortion modification spectrum 


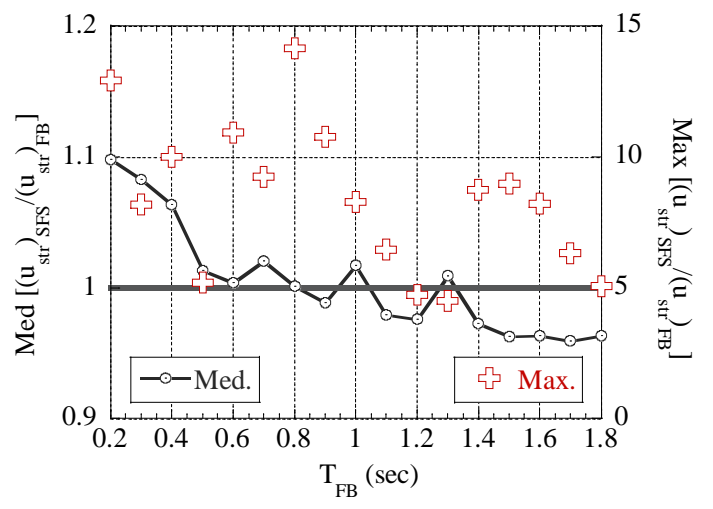

Figure 8. Structural total displacement modification spectrum in terms of median and maximum values 


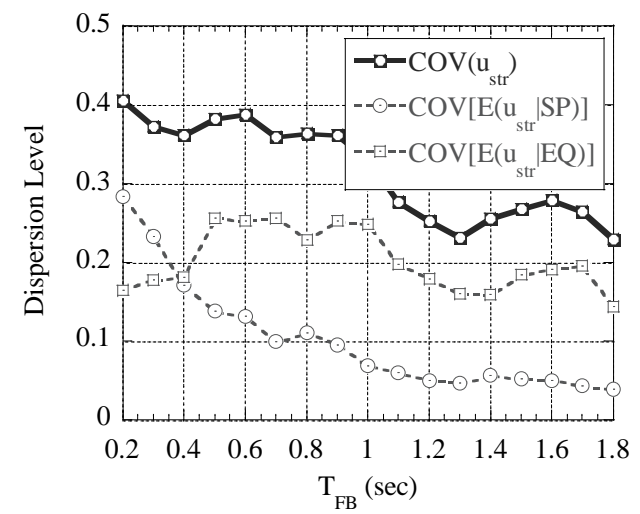

Figure 9. Dispersions in structural total displacement modification spectrum 
(a)

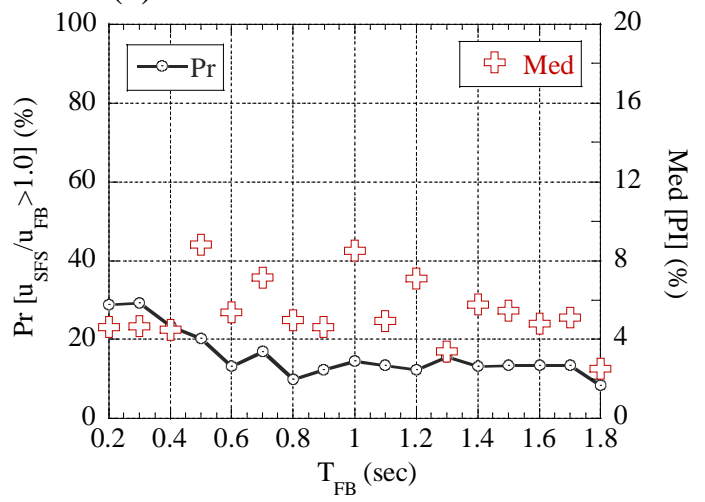

(b)

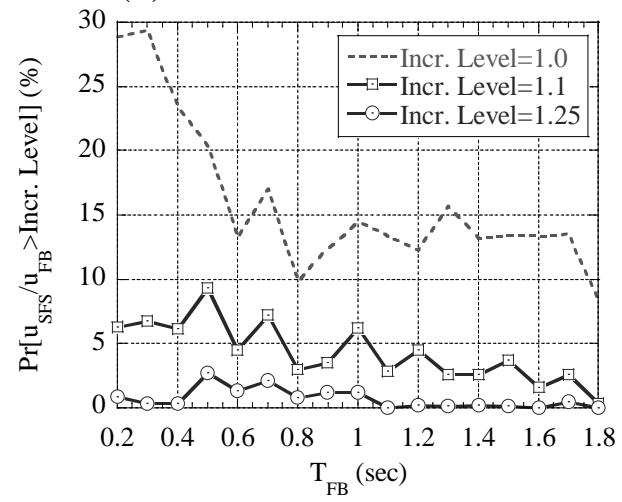

Figure 10. Quantification of structural distortion amplification 
(a)

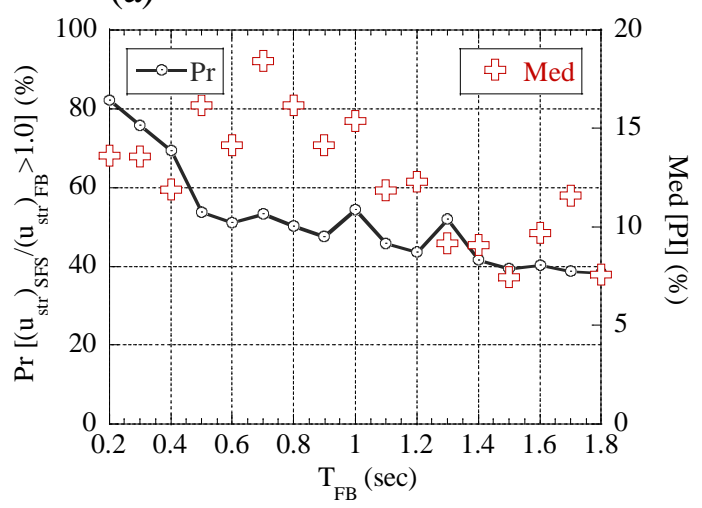

(b)

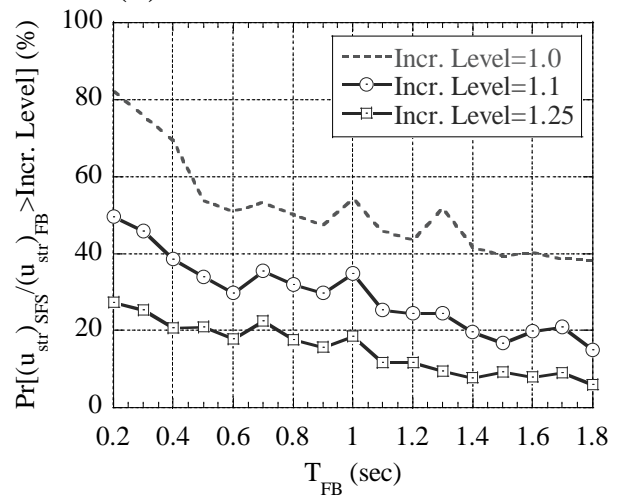

Figure 11. Quantification of structural total displacement amplification 


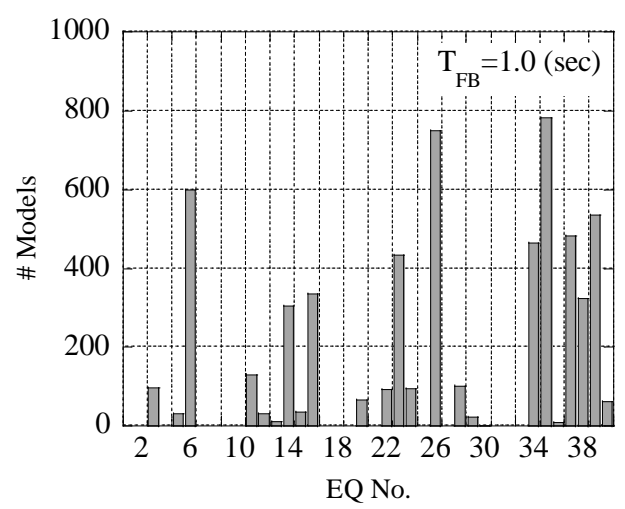

Figure 12. Histogram of earthquake motions causing $\mathrm{u}_{\mathrm{SFS}} / \mathrm{u}_{\mathrm{FB}}>1.0$ for group of models with $\mathrm{T}_{\mathrm{FB}}=1.0 \mathrm{sec}$ 

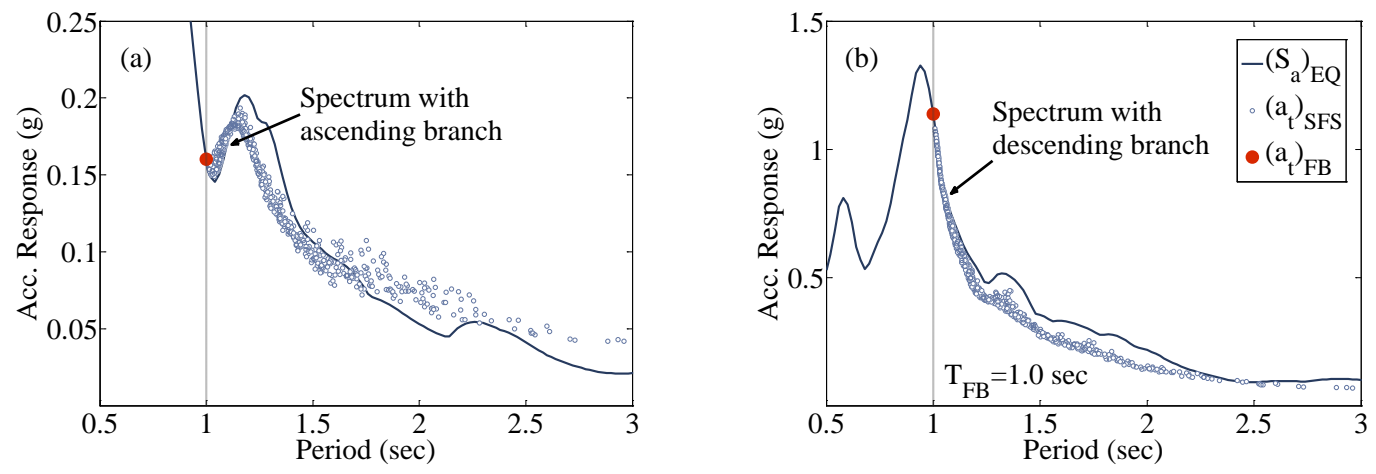

Figure 13. Earthquake acceleration response spectrum compared with maximum acceleration response of FB and SFS models for: (a) EQ23 and (b) EQ2 at $\mathrm{T}_{\mathrm{FB}}=1.0 \mathrm{sec}$ 
(a)

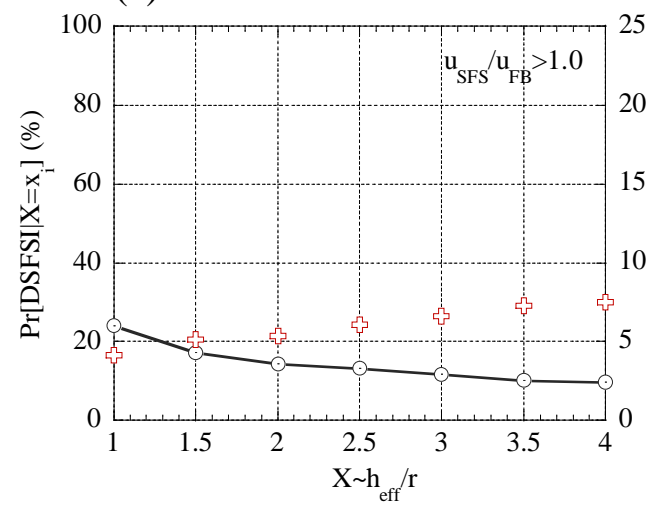

(b)

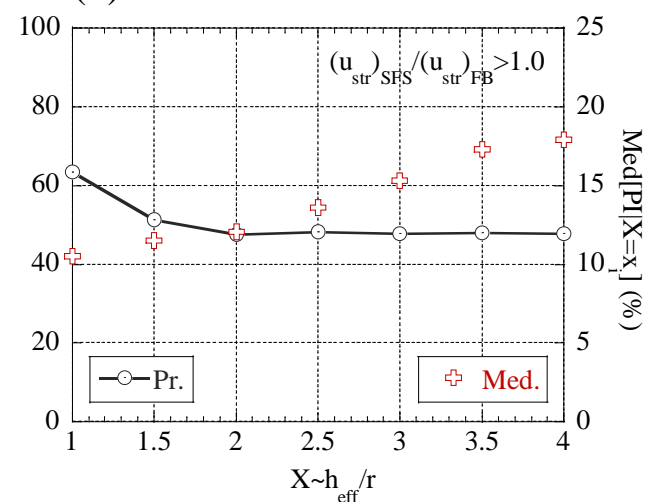

Figure 14. Quantification of DSFSI scenarios based on variation of $\tilde{h}:$ (a) amplification in structural distortion and (b) amplification in structural total displacement 
(a)

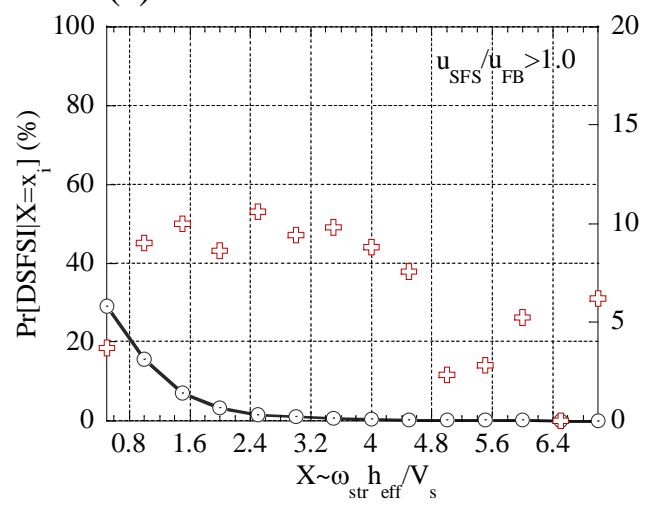

(b)

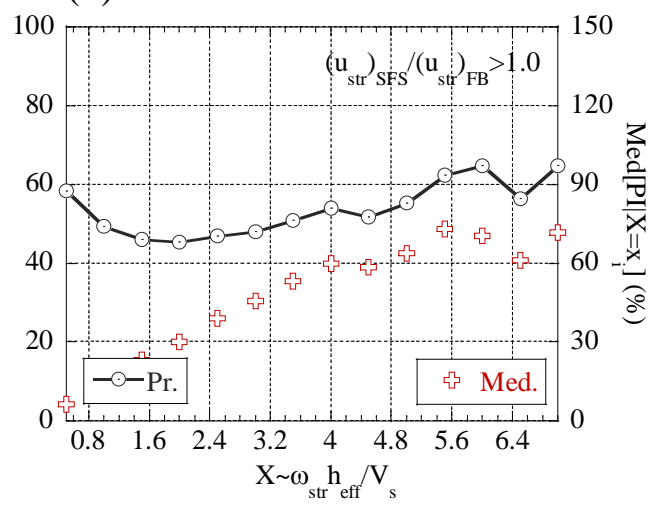

Figure 15. Quantification of DSFSI scenarios based on variation of $\widetilde{\omega}:$ (a) amplification in structural distortion and (b) amplification in structural total displacement 
Table 1. Coefficients of a soil-foundation element based on the cone model concept

\begin{tabular}{|c|c|c|c|c|}
\hline \multicolumn{2}{|c|}{ Motion } & Stiffness & Viscous damping & Added mass \\
\hline \multicolumn{2}{|c|}{ Horizontal } & $\mathrm{k}_{0}=\frac{8 \mathrm{Gr}}{2-v}$ & $\mathrm{c}_{0}=\rho \mathrm{V}_{\mathrm{s}} \mathrm{A}$ & - \\
\hline \multirow{5}{*}{ 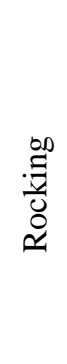 } & $v \leq 1 / 3$ & \multirow{2}{*}{$\mathrm{k}_{\varphi}=\frac{8 \mathrm{Gr} \mathrm{r}^{3}}{3(1-v)}$} & $C_{\varphi}=\rho V_{p} I_{r}$ & - \\
\hline & $1 / 3 \leq v \leq 1 / 2$ & & $c_{\varphi}=\rho\left(2 V_{s}\right) I_{r}$ & $\Delta \mathrm{m}_{\varphi}=1.2(v-1 / 3) \rho \mathrm{I}_{\mathrm{r}} \mathrm{r}$ \\
\hline & \multicolumn{4}{|c|}{ Internal mass moment of inertia } \\
\hline & $v \leq 1 / 3$ & \multicolumn{3}{|c|}{$\mathrm{m}_{\varphi}=\frac{9 \pi}{32} \rho \mathrm{I}_{\mathrm{r}} \mathrm{r}(1-v)\left(\frac{\mathrm{V}_{\mathrm{p}}}{\mathrm{V}_{\mathrm{s}}}\right)^{2}$} \\
\hline & $1 / 3 \leq v \leq 1 / 2$ & \multicolumn{3}{|c|}{$\mathrm{m}_{\varphi}=\frac{9 \pi}{8} \rho \mathrm{I}_{\mathrm{r}} \mathrm{r}(1-v)$} \\
\hline \multirow{3}{*}{\multicolumn{2}{|c|}{ Material damping }} & \multicolumn{3}{|c|}{ Additional parallel connected element $(i=0$ or $\varphi)$} \\
\hline & & \multirow{2}{*}{\multicolumn{2}{|c|}{$\begin{array}{c}\text { Viscous damping to stiffness } \mathrm{k}_{\mathrm{i}} \\
\overline{\mathrm{c}}_{\mathrm{i}}=2 \mathrm{k}_{\mathrm{i}}\left(\xi_{0} / \omega_{0}\right)\end{array}$}} & Inertial mass to damping $c_{i}$ \\
\hline & & & & $\overline{\mathrm{m}}_{\mathrm{i}}=\mathrm{c}_{\mathrm{i}}\left(\xi_{0} / \omega_{0}\right)$ \\
\hline
\end{tabular}

The parameters utilised in this table are defined as:

- $\mathbf{r}, \mathbf{A}$ and $\mathbf{I}_{\mathbf{r}}$ : Equivalent radius of the foundation, area of the foundation $\left(\mathrm{A}=\pi \mathrm{r}^{2}\right)$ and mass moment of inertia for rocking motion $\left(\mathrm{I}_{\mathrm{r}}=\pi \mathrm{r}^{4} / 4\right)$

$\bullet \boldsymbol{\rho}, \boldsymbol{v}, \mathbf{V}_{\mathbf{s}}, \mathbf{V}_{\mathbf{p}}$ and $\mathbf{G}$ : Soil mass density, Poisson's ratio, soil shear wave velocity, soil longitudinal wave velocity and soil shear modulus

- $\xi_{0}$ and $\omega_{0}$ : Equivalent soil material damping and effective frequency of SFS system 
Table 2. Ranges of variation for the selected uncertain soil parameters

\begin{tabular}{l|c}
\multicolumn{1}{c|}{ Parameter } & Range of Variation \\
\hline$\left(V_{s}\right)_{0}$ : Initial shear wave velocity & $80 \ldots 360 \mathrm{~m} / \mathrm{sec}$ \\
\hline$\left(V_{s}\right)_{s e d}\left(V_{s}\right)_{0}$ : Shear wave velocity degradation ratio & $0.15 \ldots 0.7$ \\
\hline$\rho:$ Soil mass density & $1.6 \ldots 1.9 \mathrm{t} / \mathrm{m}^{3}$ \\
\hline$v:$ Poisson's ratio & $0.3 \ldots 0.45$ \\
\hline
\end{tabular}


Table 3. Ranges of variation for $\mathrm{h}_{\text {eff }}$

\begin{tabular}{c|c}
\hline $\mathbf{T}_{\mathbf{F B}}(\mathbf{s e c})$ & $\mathbf{h}_{\text {eff }}(\mathbf{m})$ \\
\hline $0.2 \ldots 0.32$ & $2 \ldots 26.8\left(\mathrm{~T}_{\mathrm{FB}}{ }^{1.33}\right)$ \\
\hline $0.32 \ldots 0.8$ & $9.1\left(\mathrm{~T}_{\mathrm{FB}}^{1.33}\right) \ldots 26.8\left(\mathrm{~T}_{\mathrm{FB}}{ }^{1.33}\right)$ \\
\hline $0.8 \ldots 1.8$ & $9.1\left(\mathrm{~T}_{\mathrm{FB}}{ }^{1.33}\right) \ldots 20$ \\
\hline
\end{tabular}


Table 4. Ranges of variation for $\mathrm{r}$

\begin{tabular}{c|c}
\hline $\mathbf{h}_{\text {eff }}(\mathbf{m})$ & $\mathbf{r}(\mathbf{m})$ \\
\hline $2 \ldots 8$ & $2 \ldots \mathrm{h}_{\text {eff }}$ \\
\hline $8 \ldots 12$ & $\left(\mathrm{~h}_{\text {eff }} / 4\right) \ldots \mathrm{h}_{\text {eff }}$ \\
\hline $12 \ldots 20$ & $\left(\mathrm{~h}_{\text {eff }} / 4\right) \ldots 12$ \\
\hline
\end{tabular}

